Cochrane Database of Systematic Reviews

\title{
Timing and volume of fluid administration for patients with bleeding (Review)
}

Kwan I, Bunn F, Chinnock P, Roberts I

Kwan I, Bunn F, Chinnock P, Roberts I.

Timing and volume of fluid administration for patients with bleeding.

Cochrane Database of Systematic Reviews 2014, Issue 3. Art. No.: CD002245.

DOI: 10.1002/14651858.CD002245.pub2.

www.cochranelibrary.com 
TABLE OF CONTENTS

HEADER 1

ABSTRACT

PLAIN LANGUAGE SUMMARY

BACKGROUND

OBJECTIVES

METHODS

RESULTS

Figure 1.

DISCUSSION

AUTHORS' CONCLUSIONS

ACKNOWLEDGEMENTS

REFERENCES

CHARACTERISTICS OF STUDIES

APPENDICES

WHAT'S NEW

HISTORY

CONTRIBUTIONS OF AUTHORS

DECLARATIONS OF INTEREST

SOURCES OF SUPPORT 
[Intervention Review]

\section{Timing and volume of fluid administration for patients with bleeding}

Irene Kwan ${ }^{1}$, Frances Bunn², Paul Chinnock ${ }^{3}$, Ian Roberts ${ }^{3}$

1Evidence for Policy and Practice Information and Coordinating Centre (EPPI-Centre), Social Science Research Unit (SSRU), Institute of Education, University of London, London, UK. ${ }^{2}$ Centre for Research in Primary and Community Care, University of Hertfordshire, Hatfield, UK. ${ }^{3}$ Cochrane Injuries Group, London School of Hygiene \& Tropical Medicine, London, UK

Contact address: Irene Kwan, Evidence for Policy and Practice Information and Coordinating Centre (EPPI-Centre), Social Science Research Unit (SSRU), Institute of Education, University of London, 10 Woburn Square, London, WC1H 0NR, UK. I.Kwan@ioe.ac.uk, irenekwan27@gmail.com.

Editorial group: Cochrane Injuries Group.

Publication status and date: New search for studies and content updated (no change to conclusions), published in Issue 3, 2014.

Citation: Kwan I, Bunn F, Chinnock P, Roberts I. Timing and volume of fluid administration for patients with bleeding. Cochrane Database of Systematic Reviews 2014, Issue 3. Art. No.: CD002245. DOI: 10.1002/14651858.CD002245.pub2.

Copyright $\odot 2014$ The Cochrane Collaboration. Published by John Wiley \& Sons, Ltd.

\section{A B S T R A C T}

\section{Background}

Treatment of haemorrhagic shock involves maintaining blood pressure and tissue perfusion until bleeding is controlled. Different resuscitation strategies have been used to maintain the blood pressure in trauma patients until bleeding is controlled. However, while maintaining blood pressure may prevent shock, it may worsen bleeding.

\section{Objectives}

To examine the effect on mortality and coagulation times of two intravenous fluid administration strategies in the management of haemorrhagic hypovolaemia, early compared to delayed administration and larger compared to smaller volume of fluid administered.

\section{Search methods}

We searched the Cochrane Injuries Group Specialised Register, Cochrane Central Register of Controlled Trials (CENTRAL) in The Cochrane Library, Ovid MEDLINE(R), Ovid MEDLINE(R) In-Process \& Other Non-Indexed Citations, Ovid MEDLINE(R) Daily and Ovid OLDMEDLINE(R), Embase Classic + Embase (OvidSP), ISI Web of Science (SCI-Expanded and CPCI-S) and clinical trials registries. We checked reference lists of identified articles and contacted authors and experts in the field. The most recent search was run on 5 February 2014.

\section{Selection criteria}

Randomised trials of the timing and volume of intravenous fluid administration in trauma patients with bleeding. Trials in which different types of intravenous fluid were compared were excluded.

\section{Data collection and analysis}

Two authors independently extracted data and assessed trial quality.

\section{Main results}

Six trials involving a total of 2128 people were included in this review. We did not combine the results quantitatively because the interventions and patient populations were so diverse.

Early versus delayed fluid administration

Three trials reported mortality and two reported coagulation data. 
In the first trial $(\mathrm{n}=598)$ the relative risk $(\mathrm{RR})$ for death with early fluid administration was 1.26 (95\% confidence interval (CI) 1.00 to 1.58 ). The weighted mean differences (WMD) for prothrombin time and partial thromboplastin time were $2.7(95 \% \mathrm{Cl} 0.9$ to 4.5$)$ and $4.3(95 \% \mathrm{Cl}$ 1.74 to 6.9 ) seconds, respectively.

In the second trial $(n=50)$ the RR for death with early blood transfusion was 5.4 ( $95 \% \mathrm{Cl} 0.3$ to 107.1). The WMD for partial thromboplastin time was $7.0(95 \% \mathrm{Cl} 6.0$ to 8.0$)$ seconds. In the third trial $(n=1309)$ the RR for death with early fluid administration was $1.06(95 \% \mathrm{Cl} 0.77$ to 1.47$)$.

Larger versus smaller volume of fluid administration

Three trials reported mortality and one reported coagulation data.

In the first trial $(n=36)$ the RR for death with a larger volume of fluid resuscitation was $0.80(95 \% \mathrm{Cl} 0.28$ to 22.29$)$. Prothrombin time and partial thromboplastin time were 14.8 and 47.3 seconds in those who received a larger volume of fluid, as compared to 13.9 and 35.1 seconds in the comparison group.

In the second trial $(\mathrm{n}=110)$ the RR for death with a high systolic blood pressure resuscitation target (100 mm $\mathrm{Hg}$ ) maintained with a larger volume of fluid as compared to a low systolic blood pressure resuscitation target $(70 \mathrm{~mm} \mathrm{Hg})$ maintained with a smaller volume of fluid was $1.00(95 \% \mathrm{Cl} 0.26$ to 3.81$)$. In the third trial $(n=25)$ there were no deaths.

\section{Authors' conclusions}

We found no evidence from randomised controlled trials for or against early or larger volume of intravenous fluid administration in uncontrolled haemorrhage. There is continuing uncertainty about the best fluid administration strategy in bleeding trauma patients. Further randomised controlled trials are needed to establish the most effective fluid resuscitation strategy.

\section{PLAIN LANGUAGE SUMMARY}

\section{Varying the timing or the volume of intravenous fluids given to people with uncontrolled bleeding due to injury}

About one third of injury deaths are due to shock from blood loss. Preventing shock in people with uncontrolled bleeding is, therefore, very important and is generally done by giving fluids intravenously. The aim is to maintain blood pressure and reduce tissue damage. The composition of these fluids can vary, and there have been systematic reviews comparing different fluid types, but the volume of fluid given and the time at which it is given can also vary. It not yet clear which timing and which volume are the most effective.

The authors searched for relevant medical research reports and found six randomised controlled trials involving a total of 2128 people. In each study, people with uncontrolled bleeding were randomly assigned to receive one treatment or another. Three studies were about the amount of fluid given (more or less), and three studies were about giving fluid at different times following injury (sooner or later). The authors were interested in finding out which treatments were better, to reduce deaths and to enable blood clotting. Blood clotting was measured by prothrombin time and partial thromboplastin time during fluid administration.

The review of trials found that there is uncertainty about the best time to give fluid and what volume of fluid should be given. While increasing fluids will maintain blood pressure, it may also worsen bleeding by diluting clotting factors in the blood.

The first version of this review was published in 2000 and included these six trials. The authors searched for new, relevant studies in 2003 , 2008 and 2014 but none were found. The authors will look for studies in 2020, and any new information will be incorporated into the review. 


\section{B A C K G R O U N D}

In 1990 approximately five million people died worldwide as a result of injury (Murray 1996). For people younger than 35 years, injury is now the leading cause of death. Nevertheless, the global epidemic of injury is only beginning. It is estimated that by 2020 , deaths from injury will have increased from 5.1 million to 8.4 million (Murray 1997). About one third of injury deaths are due to haemorrhagic shock (Deakin 1994). Acute blood loss following injury leads to a reduction in tissue perfusion and tissue oxygen delivery that, if prolonged, cause lactic acidosis and organ failure. Treatment of haemorrhagic shock involves maintaining blood pressure and tissue perfusion until the bleeding is controlled. Over the past 50 years a number of resuscitation strategies have been used to maintain the blood pressure in trauma patients until bleeding is controlled. The evidence for the effectiveness of these approaches has been the subject of a number of systematic reviews by the Cochrane Injuries Group and by others.

\section{Pre-hospital use of medical anti-shock trousers}

Medical anti-shock trousers (MAST) were first used in the Vietnam War to stabilise patients with haemorrhagic shock during transportation. After the war, MAST became widely used in the care of bleeding trauma patients. MAST increase blood pressure by compressing the blood vessels in the legs, thus increasing systemic vascular resistance, and by shunting blood from the lower body to the brain, heart and lungs. It was hoped that by increasing venous return to the heart, MAST would maintain the blood flow to vital organs until definitive care was given. Nevertheless, a systematic review of randomised controlled trials of MAST use in pre-hospital trauma care provided no evidence that MAST increase survival, and a suggestion that they may increase the risk of death. The pooled relative risk of death with MAST was $1.13(95 \% \mathrm{Cl} 0.97$ to 1.32) (Roberts 1999).

\section{Paramedic ambulance crews}

In high-income countries, an increasing number of ambulance crews include a paramedic trained in advance life support. Paramedics receive extra training in intubation, intravenous cannulation, and the administration of intravenous fluids. Only a small proportion of paramedic-attended trauma patients require intubation (1\%), but a larger proportion (18\%) receive intravenous fluids (Nicholl 1998). Because of the strong conviction amongst the public and medical profession that paramedic intervention is beneficial, it has been difficult to conduct randomised controlled trials comparing paramedic and non-paramedic trauma care. However, a review and meta-analysis of four cohort studies gave a significantly increased $(P=0.03)$ risk of death in paramedicattended patients (relative risk (RR) 1.26) (Nicholl 1998). Because of the potential for confounding by injury severity, the validity of inferences from cohort studies must be questioned. Nevertheless, the results are consistent with the hypothesis that efforts by paramedics to raise the blood pressure of bleeding trauma patients may be counterproductive.

\section{Colloid fluid resuscitation}

Intravenous fluid administration, with colloid or crystalloid solutions, is the mainstay of the non-surgical management of bleeding trauma patients. Colloids are better than crystalloid solutions in expanding the circulation because they are retained within the blood vessels to a greater extent. Crystalloid solutions rapidly leak out of the blood vessels into the interstitial spaces. After a colloid infusion, the increase in the circulating volume is about the same as the volume of colloid infused, whereas only about one quarter of the volume of a crystalloid infusion remains in the blood vessels (Weil 1999). Although colloids are effective in expanding the circulation there is no evidence that this improves outcomes in critically ill patients (Perel 2013).

The systematic reviews of MAST, paramedic resuscitation and colloid administration call into question the benefits of raising the blood pressure in bleeding trauma patients. But by what mechanisms could fluid resuscitation adversely affect the outcome? Stern, using a swine model of near-fatal haemorrhage, found that attempts to restore blood pressure with crystalloid resulted in increased haemorrhage volume and markedly higher mortality (Stern 1993). It was postulated that the increased pulse pressure from crystalloid resuscitation might cause the mechanical disruption of blood clots and worsen bleeding. It has also been proposed that fluid administration might worsen bleeding by diluting clotting factors. In view of the concerns raised by the previous systematic reviews, and by the results of animal models of haemorrhagic hypovolaemia, we have conducted a systematic review of the effect on mortality of early versus delayed fluid resuscitation, and of larger versus smaller fluid volumes.

\section{O B JECT IVES}

To examine the effect on mortality and coagulation times of two intravenous fluid administration strategies in the management of haemorrhagic hypovolaemia, early compared to delayed administration and larger compared to smaller volume of fluid administered.

\section{METHODS}

\section{Criteria for considering studies for this review}

\section{Types of studies}

All randomised controlled trials of the timing or volume of intravenous fluid administration in haemorrhagic hypovolaemia.

\section{Types of participants}

People of all ages with haemorrhagic hypovolaemia of traumatic or non-traumatic origin. Because the physiological response to bleeding and to fluid resuscitation is likely to be similar among people with internal bleeding (for example a bleeding peptic ulcer) and those with external bleeding (for example penetrating trauma), both types of participants were included.

\section{Types of interventions}

Intravenous fluids including crystalloid solutions, colloids, plasma and blood. Trials in which the timing or volume of fluid administration was confounded by the type of intravenous fluid given, for example a trial comparing the administration of $1000 \mathrm{ml}$ of colloid with $500 \mathrm{ml}$ of blood, were excluded.

\section{Types of outcome measures}

\section{Primary outcomes}

- Mortality from all causes at the end of the follow-up period scheduled for each trial 
We sought mortality data in simple categorical form, and we did not extract data on time to death. If a report did not include the numbers of deaths in each group, we sought these data from the authors.

\section{Secondary outcomes}

- Prothrombin time

- Partial thromboplastin time during fluid administration

\section{Search methods for identification of studies}

In order to reduce publication and retrieval bias we did not restrict our search by language, date or publication status.

\section{Electronic searches}

The Cochrane Injuries Group Trials Search Co-ordinator searched the following:

1. Cochrane Injuries Group Specialised Register (31st January 2014);

2. Cochrane Central Register of Controlled Trials (CENTRAL) in The Cochrane Library (2014, Issue 1 of 12);

3. Ovid MEDLINE(R), Ovid MEDLINE(R) In-Process \& Other Non-Indexed Citations, Ovid MEDLINE(R) Daily and Ovid OLDMEDLINE(R (1946 to 5th February 2014);

4. Embase Classic + Embase (OvidSP) (1947 to 5th February 2014);

5. ISI Web of Science: Science Citation Index Expanded (SCIExpanded) (1970 to February 2014);

6. ISI Web of Science: Conference Proceedings Citation IndexScience (CPCI-S) (1990 to February 2014).

Search notes and strategies can be found in Appendix 1.

\section{Searching other resources}

We checked the reference lists of all included studies and contacted authors and experts in the field. The Science Citation Index was checked for eligible papers that cited two of the trials (Bickell 1994; Blair 1986) included in this review.

\section{Data collection and analysis}

\section{Selection of studies}

For the original version of the review, one author (IK) examined the electronic search results for reports of possibly relevant trials and these reports were then retrieved in full. The first review author (IK) also contacted experts in the field for unpublished and ongoing trials. A second review author (FB) examined $10 \%$ of the electronic search results to check for agreement on eligibility criteria. Two review authors (FB, IK) applied the selection criteria independently to the trial reports, resolving disagreements by discussion with a third (IR).

For the 2014 update, PC screened all the search results. IK, IR and FB each screened one third of the search results for the purpose of dual screening.

\section{Data extraction and management}

For the original version of the review, two authors (IK, FB) independently extracted information on the following: method of allocation concealment, number of randomised patients, types of participants and the interventions, loss to follow-up and length of follow-up. The outcome data sought were numbers of deaths, prothrombin time and partial thromboplastin time. The authors were not blinded to the study authors or journal when doing this. Results were compared and any differences resolved by discussion.

Where there was insufficient information in the published report we attempted to contact the authors for clarification.

\section{Assessment of risk of bias in included studies}

Since there is evidence that the quality of allocation concealment particularly affects the results of studies, two authors (IK, FB) scored this quality on the scale used by Higgins 2011 as shown below, assigning 'High risk of bias' to poorest quality and 'Low risk of bias' to best quality trials.

- Low risk of bias: trials deemed to have taken adequate measures to conceal allocation (i.e. central randomisation; serially numbered, opaque, sealed envelopes; or other description that contained elements convincing the review authors of concealment).

- Unclear risk of bias: trials in which the authors either did not report an allocation concealment approach at all or reported an approach that did not fall into one of the other categories.

- High risk of bias: trials in which concealment was inadequate (such as alternation or reference to case record numbers or to dates of birth).

Where the method used to conceal allocation was not clearly reported, the author(s) were contacted, if possible, for clarification. We then compared the judgement assigned and resolved differences by discussion.

\section{Data synthesis}

The following comparisons were made:

- early versus delayed intravenous fluids administration;

- larger versus smaller volumes of intravenous fluids administration.

The relative risk of death and $95 \%$ confidence interval $(95 \% \mathrm{Cl})$ were calculated, such that a relative risk of more than 1 indicated a higher risk of death in the first group named. The relative risk was chosen as it is more readily applied to the clinical situation. The weighted mean difference was calculated for coagulation times.

Because of differences in the types of patients and in the nature of the trial interventions we did not pool the data in our analysis.

\section{RE S U L T S}

\section{Description of studies}

The six included studies were retrieved by the original search. The most recent search retrieved 1221 references (Figure 1) and all search results were scanned by two review authors for potentially relevant studies. No new trials that met the inclusion criteria were identified from these updated search results. 
Figure 1. Study flow diagram.

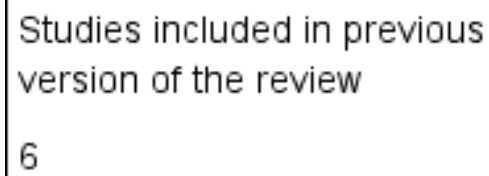




\section{A. Early versus delayed intravenous fluids administration}

\section{Bickell 1994}

This trial compared early versus delayed administration of Ringer's acetate solution, an isotonic crystalloid, in patients with penetrating torso injuries during the pre-hospital phase. Participants were adults over 16 years of age, with gunshot or stab wounds to the torso, and who had a systolic blood pressure of $<90$ $\mathrm{mm} \mathrm{Hg}$. Participants with head injury, a Revised Trauma Score of zero or minor injuries were excluded. During the trial, 22 patients $(8 \%)$ in the delayed resuscitation group were inadvertently given fluid prior to surgery in violation of the protocol. Follow-up was until hospital discharge.

\section{Blair 1986}

This trial compared early versus delayed blood transfusion in patients with acute gastrointestinal haemorrhage during the first 24 hours after admission. Patients with oesophageal varices were excluded because of abnormal coagulation related to liver diseases. Follow-up was until hospital discharge.

\section{Turner 2000}

This trial compared early versus no or delayed fluid administration in trauma patients. Participants were all trauma patients with moderate to severe injuries, over the age of 16 years. Patients who were pregnant or without vital signs were excluded. The fluids given were crystalloids. Protocol compliance was poor with $31 \%$ of patients in the early fluid group receiving fluids and $80 \%$ of the delayed or no fluid group not given fluids. Follow-up was for six months.

\section{B. Larger versus smaller volume of intravenous fluids administration}

Dunham 1991

This trial compared fluid resuscitation using the rapid infusion system and conventional fluid administration method in trauma patients during the first 24 hours of admission. Participants were between 14 and 60 years of age and had a systolic blood pressure of $<90 \mathrm{~mm} \mathrm{Hg}$. Patients with a Glasgow Coma Score of $<5$, cardiac arrest, quadriplegia and myocardial infarct on admission were excluded. Fluids given included red blood cells, platelets, fresh frozen plasma and crystalloids. Follow-up was until hospital discharge.

\section{Dutton 2002}

This trial compared the maintenance of target systolic blood pressures of 70 and $100 \mathrm{~mm} \mathrm{Hg}$ respectively with fluid restriction (Plasma, Plasmalyte-A and red blood cells in the first 24 hours) in patients with blunt and penetrating trauma injuries. All participants suffered haemorrhagic shock with a systolic blood pressure (SBP) of $<90 \mathrm{~mm} \mathrm{Hg}$. Patients with head or spinal cord injury were excluded. The length of the follow-up period was until death or hospital discharge.

\section{Fortune 1987}

This trial compared the maintenance of the haematocrit at $30 \%$ and $40 \%$ respectively with blood transfusion in patients following acute injuries and haemorrhage, during the first 72 hours of admission. All participants had sustained Class III or IV haemorrhage with a systolic blood pressure of $<90 \mathrm{~mm} \mathrm{Hg}$, heart rate $>100$ beats per minute. Follow-up was for three days.

\section{Risk of bias in included studies}

\section{A. Early versus delayed intravenous fluids administration}

Bickell 1994

Randomisation was by alternate day allocation, which allowed foreknowledge of treatment allocation. Data were analysed as randomised, on an intention-to-treat basis. Blinding of outcome assessment was not stated. There was no loss to follow-up.

\section{Blair 1986}

Contact with the author of this trial established the adequacy of the randomisation method used. Allocation was by opening sealed envelopes at the time of patient presentation. Blinding of outcome assessment was not stated. Data were analysed as randomised, on an intention-to-treat basis. There was no loss to follow-up.

\section{Turner 2000}

Paramedics rather than trauma patients were randomised using computer-generated random numbers, stratified by base stations. The paramedics crossed over to the alternate fluid protocol halfway through the trial and they were not blinded. Data were analysed as randomised, on an intention-to-treat basis. There was no blinding of outcome assessment.

\section{B. Larger versus smaller volume of intravenous fluids administration}

Dunham 1991

The methods of randomisation and allocation concealment were unclear. Blinding of outcome assessment was not stated. Data on eight patients who died during the first 12 hours were excluded from the analysis except for the outcome death.

\section{Dutton 2002}

Randomisation was by selecting the next numbered envelope from a supply maintained in the Trauma Resuscitation Unit. The envelopes were made up in batches of 20 (10 to each group), thoroughly mixed and then numbered for selection. Allocation was blinded to all unit personnel prior to enrolment. Only the patients were blinded to the allocation in this trial after randomisation. Data were analysed as randomised, on an intention-to-treat basis. Blinding of outcome assessment was not stated. There was no loss to follow-up.

\section{Fortune 1987}

Contact with the co-author of this trial established the adequacy of the randomisation method used. Sequences of random allocations were generated by a statistician not involved with the study, in sets of sealed opaque envelopes, differentiated by sex and age groups. Both patients and physicians had no prior knowledge of which arm the patient would be assigned to. Blinding of outcome assessment was not stated. There was no loss to follow-up.

The characteristics of each trial are listed in Characteristics of included studies.

\section{Effects of interventions}

\section{A. Early versus delayed fluid administration}

One trial (Bickell 1994) reported mortality and coagulation time for a total of 598 hypotensive trauma patients with penetrating torso injuries. Mortality was $116 / 309(38 \%)$ in the early and $86 / 289$ $(30 \%)$ in the delayed administration group. The relative risk for 
death with early fluid administration was $1.26(95 \% \mathrm{Cl} 1.00$ to 1.58$)$. Prothrombin time and partial thromboplastin time were 14.1 and 31.8 seconds in the early administration group as compared to 11.4 and 27.5 seconds in the delayed administration group. The weighted mean differences (WMD) for prothrombin time and partial thromboplastin time were 2.7 ( $95 \% \mathrm{Cl} 0.90$ to 4.5 ) and 4.3 seconds $(95 \% \mathrm{Cl} 1.7$ to 6.9$)$ respectively.

One trial (Blair 1986) reported mortality and coagulation time for a total of 50 hypotensive patients with acute upper gastrointestinal haemorrhage. Mortality was $2 / 24(8 \%)$ in the early as compared to $0 / 26(0 \%)$ in the delayed transfusion group. The relative risk for death with early blood transfusion was 5.4 ( $95 \% \mathrm{Cl} 0.3$ to 107.1$)$. The activated partial thromboplastin time was 48 in the early group as compared to 41 seconds in the delayed administration group. The WMD for partial thromboplastin time was 7.0 seconds $(95 \% \mathrm{Cl} 6.0$ to 8.0).

In one trial (Turner 2000) on a total of 1309 trauma patients, mortality was $73 / 699(10.4 \%)$ in the early as compared to $60 / 610$ $(9.8 \%)$ in the delayed or no fluid administration group. The relative risk for death with early fluid administration was 1.06 (95\% Cl 0.77 to 1.47$)$. There were no data on coagulation times.

\section{B. Larger versus smaller volume of fluid administration}

One trial (Dunham 1991) reported mortality and coagulation time for a total of 36 hypotensive trauma patients. Mortality was $5 / 20(25 \%)$ in the group who received a larger volume of fluids, administered conventionally, as compared to $5 / 16(31 \%)$ in the group who received a smaller volume of fluids administered using the Rapid Infusion System. The relative risk for death was 0.80 $(95 \% \mathrm{Cl} 0.28$ to 2.29$)$. Prothrombin time and partial thromboplastin time were 14.8 and 47.3 seconds in the group who received a larger volume of fluid compared to 13.9 and 35.1 seconds in the comparison group.

In one trial (Dutton 2002) on a total of 110 hypotensive patients with blunt and penetrating injuries, mortality was $4 / 55(7.3 \%)$ in the group administered a larger volume and 4/55 (7.3\%) in the group administered a smaller volume $(1000 \mathrm{ml}$ less than in the intervention group). The relative risk for death was 1.00 ( $95 \% \mathrm{Cl} 0.26$ to 3.81 ). There were no data on coagulation times.

In one trial (Fortune 1987) on a total of 25 hypotensive patients with acute injury and haemorrhage, there were no data on mortality in either of the groups administered larger or smaller volumes of blood. Contact with the co-author established that there were no deaths in either group. There were no data on coagulation times.

\section{DISCUSSION}

This review found insufficient evidence for or against the use of early or larger volume fluid resuscitation in the treatment of uncontrolled haemorrhage. While vigorous fluid resuscitation may be life-saving in some patients, results from clinical trials are inconclusive.

Every year, 10 s of 1000 s of patients receive intravenous fluids in the management of bleeding. The Advanced Trauma Life Support (ATLS) protocol of the American College of Surgeons recommends the liberal use of isotonic crystalloid to correct hypotension in bleeding trauma patients. Nevertheless, we could find no reliable evidence to support or not to support this recommendation. While we cannot exclude the possibility that we overlooked a large highquality randomised controlled trial showing that early or larger volume fluid resuscitation is beneficial, we believe that this is unlikely. To identify eligible trials we screened over 6000 potentially relevant reports, searched the reference lists of included trials, and contacted authors and experts in the field.

Six published trials were reviewed. Due to their heterogeneity in terms of types of patients and types of fluids used, we did not attempt to perform a meta-analysis of the studies.

Death was chosen as the primary endpoint in this review for two reasons. First, death is a clinically relevant outcome that matters to patients. Second, death is not prone to measurement error or to reporting bias as are pathophysiological endpoints. Mortality data were available for all six included trials, three on the effect of early fluid resuscitation (Bickell 1994; Blair 1986; Turner 2000) and three on the effect of larger volume fluid resuscitation (Dunham 1991; Dutton 2002; Fortune 1987). Three trials examined the effect of fluid administration on coagulation. Clotting times were significantly elevated in the immediate resuscitation groups (Bickell 1994; Blair 1986) and the group who received a larger volume (Dunham 1991). The method of randomisation was inadequate in two trials (Bickell 1994; Turner 2000) and unclear in another (Dunham 1991). Allocation concealment was inadequate in two trials (Bickell 1994; Turner 2000). Because inadequate randomisation and poorly concealed allocation can bias the results of randomised controlled trials, and because this bias can be large and can operate in either direction, the impact of early or larger volume fluid resuscitation on mortality remains difficult to estimate.

Interpretation of results also needs to be made cautiously due to the heterogeneous nature of the traumatic injuries encountered in these trials. Haemorrhagic shock can be caused by a variety of underlying anatomic injuries. Some of these injuries, such as posterior pelvic fractures, may be more amenable to hypotensive management maintained by a smaller volume of fluid than liver injuries where haemostasis can be difficult to achieve (Dutton 2002).

The use of medical anti-shock trousers, early and larger volume fluid administration and colloid resuscitation are based on the idea that raising the blood pressure in bleeding trauma patients will maintain tissue perfusion and so prevent haemorrhagic shock and its consequences. However, while maintaining blood pressure may prevent shock, it may worsen bleeding. In view of the lack of evidence for or against the effectiveness of currently recommended resuscitation protocols and the potential for harm, the balance of risks and benefits of contemporary resuscitation practice warrants careful consideration. Further randomised controlled trials are required to identify the most effective strategies for the fluid management of bleeding trauma patients.

\section{AUTHORS' CONCLUSIONS}

\section{Implications for practice}

We found no evidence for or against the use of early or larger volume intravenous fluid administration in uncontrolled haemorrhage. There is uncertainty about the effectiveness of fluid resuscitation in patients with bleeding following trauma. 


\section{Implications for research}

Large, well concealed, randomised controlled trials are urgently needed to establish the optimal fluid resuscitation strategy in haemorrhaging trauma patients, with a focus on specific types of injuries likely to benefit from the appropriate resuscitation strategy in terms of timing and volume of fluids given.

\section{A C K N OWLEDGEMENTS}

We thank the trialists and their co-authors for supplying additional information. We thank Drs D Mohan, C Mock, R Norton, M Varghese of the WHO Pre-Hospital Trauma Care Steering Committee for their comments and advice on the review, and Mr Reinhard Wentz for his help with the searching. 


\section{R E F E R E N C E S}

\section{References to studies included in this review}

Bickell 1994 \{published data only\}

* Bickell WH, Wall MJ, Pepe PE, Martin RR, Ginger VF, Allen MK, et al. Immediate versus delayed fluid resuscitation for hypotensive patients with penetrating torso injuries. New England Journal of Medicine 1994;331(17):1105-9.

Martin RR, Bickell WH, Pepe PE, Burch JM, Mattox KL. Prospective evaluation of preoperative fluid resuscitation in hypotensive patients with penetrating truncal injury: a preliminary report. Journal of Trauma 1992;33(3):354-62.

Blair 1986 \{published data only\}

Blair SD, Janvrin SB, McCollum CN, Greenhalgh RM. Effect of early blood transfusion on gastrointestinal haemorrhage. British Journal of Surgery 1986;73(10):783-5.

Dunham 1991 \{published data only\}

Dunham CM, Belzberg H, Lyles R, Weireter L, Skurdal D, Sullivan $\mathrm{G}$, et al. The rapid infusion system: a superior method for the resuscitation of hypovolemic patients. Resuscitation 1991;21(2-3):207-27.

\section{Dutton 2002 \{published data only\}}

Dutton RP, MacKenzie CF, Scalea TM. Hypotensive resuscitation during active haemorrhage: impact on in-hospital mortality. Journal of Trauma 2002;52:1141-6.

\section{Fortune 1987 \{published data only\}}

Fortune JB, Feustel PJ, Saifi J, Stratton HH, Newell JC, Shah DM. Influence of hematocrit on cardiopulmonary function after acute hemorrhage. Journal of Trauma 1987;27(3):243-9.

\section{Turner 2000 \{published data only\}}

Turner J, Nicholl J, Webber L, Cox H, Dixon S, Yates D. A randomised controlled trial of pre-hospital intravenous fluid replacement therapy in serious trauma. Health Technology Assessment 2000;4(31):1-47.

\section{References to studies excluded from this review}

Gondos 2010 \{published data only\}

Gondos T, Marjanek Z, Ulakcasi Z, Szabo Z, Bogar L, Karolyi M, et al. Short-term effectiveness of different volume replacement therapies in postoperative hypovolaemic patients. European Journal of Anaesthesiology 2010;27:794-800. [DOI: 10.1097/ EJA.0b013e32833b3504]

\section{Yang 2013 \{published data only\}}

Yang WJ, Feng QG, Wei K, Wang W, Zhao XF, Li C, et al. The impact of early restrictive positive fluid balance strategy on the prognosis of patients with severe trauma. Zhonghua Wei Zhong Bing Ji Jiu Yi Xue 2013;25(1):36-9. [DOI: 10.3760/ cma.j.issn.2095-4352.2013.01.010]

\section{Additional references}

\section{Deakin 1994}

Deakin CD, Hicks IR. AB or ABC: pre-hospital fluid management in major trauma. Journal of Accident and Emergency 1994;11(3):154-7.

\section{Higgins 2011}

Higgins JPT, Green S (editors). Cochrane Handbook for Systematic Reviews of Interventions Version 5.1.0 [updated March 2011]. Available from www.cochrane-handbook.org: The Cochrane Collaboration, 2011.

\section{Murray 1996}

Murray CJL, Lopez AD. Global Statistics: a compendium of incidence, prevalence and mortality estimates for over 200 conditions. Boston: Harvard School of Public Health, Harvard University Press, 1996.

\section{Murray 1997}

Murray CLJ, Lopez AD. Alternative projections of mortality and disability by cause 1990-2020: Global Burden of Disease Study. Lancet 1997;349(9064):1498-504.

\section{Nicholl 1998}

Nicholl J, Hughes S, Dixon S, Turner J, Yates D. The costs and benefits of paramedic skills in pre-hospital trauma care. Health Technology Assessment 1998; Vol. 2, issue 17:1-72.

\section{Perel 2013}

Perel P, Roberts I, Ker K. Colloids versus crystalloids for fluid resuscitation in critically ill patients. Cochrane Database of Systematic Reviews 2013, Issue 2. [DOI: 10.1002/14651858.CD000567.pub3]

\section{Roberts 1999}

Roberts I, Blackhall K, Dickinson KJ. Medical anti-shock trousers (pneumatic anti-shock garments) for circulatory support in patients with trauma. Cochrane Database of Systematic Reviews 1999, Issue 4. [DOI: 10.1002/14651858.CD001856]

\section{Stern 1993}

Stern SA, Dronen SC, Birrer P, Wang X. Effect of blood pressure on hemorrhage volume and survival in a near-fatal hemorrhage model incorporating a vascular surgery. Annals of Emergency Medicine 1993;22(2):155-63.

\section{Weil 1999}

Weil MH. Crystalloids, colloids and fluid compartments. Critical Care Medicine 1999;27(1):3.

* Indicates the major publication for the study 
CHARACTERISTICS OF STUDIES

Characteristics of included studies [ordered by study ID]

Bickell 1994

\begin{tabular}{|c|c|}
\hline Methods & Randomised controlled trial \\
\hline Participants & $\begin{array}{l}598 \text { trauma patients }>16 \text { years of age with penetrating injuries and hypotension } \\
\text { Mean age }=31 \text { years } \\
\text { Exclusion: pregnancy, Revised Trauma Score }=0 \text {, minor injuries not requiring surgery }\end{array}$ \\
\hline Interventions & $\begin{array}{l}\text { 1) } 870 \mathrm{ml} \text { of Ringer's solution pre-hospital ( } n=309) \\
\text { 2) } 92 \mathrm{ml} \text { of Ringer's solution with IV cannulation pre-hospital ( } n=289)\end{array}$ \\
\hline Outcomes & $\begin{array}{l}\text { - haemodynamic variables } \\
\text { - amount of fluids given } \\
\text { - intra-operative blood loss } \\
\text { - post-operative } \\
\text { - complications } \\
\text { - process of care } \\
\text { - death }\end{array}$ \\
\hline Notes & $\begin{array}{l}\text { Patients in both groups were treated with a standard paramedical protocol as appropriate until after IV } \\
\text { cannulation. } \\
22 / 289(8 \%) \text { in delayed fluids group were inadvertently given fluids in violation of the protocol. Results } \\
\text { were analysed as randomised on an intention-to-treat basis. }\end{array}$ \\
\hline
\end{tabular}

\section{Risk of bias}

\begin{tabular}{lll}
\hline Bias & Authors' judgement & Support for judgement \\
\hline $\begin{array}{l}\text { Allocation concealment } \\
\text { (selection bias) }\end{array}$ & High risk & Allocation by alternation - odd and even numbered days of the month \\
\hline
\end{tabular}

\section{Blair 1986}

\begin{tabular}{ll}
\hline Methods & Randomised controlled trial \\
\hline Participants & 50 patients with acute severe upper gastrointestinal haemorrhage \\
& Mean age $=62$ \\
& Exclusion: patients with oesophageal varices due to abnormal coagulation \\
\hline Interventions & 1) $\geq 2$ units of blood in first $24 \mathrm{hr}(\mathrm{n}=24)$ \\
& 2) No blood transfusion during first $24 \mathrm{hr}(\mathrm{n}=26)$ \\
\hline Outcomes & - coagulation times \\
& - haematocrit \\
& - volume of blood given \\
\hline
\end{tabular}


Blair 1986 (Continued)

\section{Risk of bias}

\begin{tabular}{lll}
\hline Bias & Authors' judgement & Support for judgement \\
\hline $\begin{array}{l}\text { Allocation concealment } \\
\text { (selection bias) }\end{array}$ & Low risk & Allocation by opening sealed envelopes \\
\hline
\end{tabular}

Dunham 1991

\begin{tabular}{ll}
\hline Methods & Randomised controlled trial \\
\hline Participants & 36 trauma patients $>14<60$ years of age with hypotension \\
& Mean age $=35$ \\
& Exclusion: Glasgow Coma Score $<5$, cardiac arrest, quadriplegia, myocardial infarct
\end{tabular}

\begin{tabular}{|c|c|}
\hline Interventions & $\begin{array}{l}\text { 1. 23,661ml of IV fluids (red blood cells, fresh frozen plasma, platelets and Plasmalyte-A) in first } 24 \text { hours } \\
\text { via conventional fluid administration (CFA) }(n=20) \\
\text { 2. } 20,224 \mathrm{ml} \text { of IV fluids (red blood cells, fresh frozen plasma, platelets and Plasmalyte-A, given via the } \\
\text { RIS (Rapid Infusion System) }(n=16)\end{array}$ \\
\hline Outcomes & $\begin{array}{l}\text { - } \text { blood loss } \\
\text { - } \text { temperature } \\
\text { - } \text { haematocrit } \\
\text { - } \text { coagulation times } \\
\text { - base excess } \\
\text { - ionised calcium } \\
\text { - costs } \\
\text { - death }\end{array}$ \\
\hline
\end{tabular}

Notes Data from 3/20 patients in CFA group and 5/16 patients in RIS group who died in the first 12 hours were
excluded from subsequent analyses except for death.

\section{Risk of bias}

\begin{tabular}{lll}
\hline Bias & Authors' judgement & Support for judgement \\
\hline $\begin{array}{l}\text { Allocation concealment } \\
\text { (selection bias) }\end{array}$ & Unclear risk & Allocation unclear \\
\hline
\end{tabular}

Dutton 2002

\begin{tabular}{ll}
\hline Methods & Randomised controlled trial \\
\hline Participants & 110 trauma patients $>16,<55$ years of age with blunt and penetrating injuries and in shock \\
& $\begin{array}{l}\text { Mean age }=31 \\
\text { Exclusion: pregnancy, no pulse, head or spinal injury, known end-organ ischaemic disease }\end{array}$ \\
\hline Interventions & $\begin{array}{l}\text { 1. Bolus of fluids (plasma, Plasmalyte-A and packed red blood cells) to maintain systolic blood pressure } \\
\text { of }>100 \mathrm{mmHg}(\mathrm{n}=55)\end{array}$
\end{tabular}


Dutton 2002 (Continued)

2. $1000 \mathrm{ml}$ less of fluids (plasma, Plasmalyte-A and packed red blood cells) to maintain a lower blood pressure of $70 \mathrm{mmHg}(n=55)$

\begin{tabular}{ll}
\hline Outcomes & duration of bleeding \\
& $\cdot$ average ISS \\
$\cdot$ & death \\
\hline
\end{tabular}

Notes All patients maintained at a haematocrit of at least $25 \%$.

Results analysed as randomised on an intention-to-treat basis.

\section{Risk of bias}

\begin{tabular}{lll}
\hline Bias & Authors' judgement & Support for judgement \\
\hline $\begin{array}{l}\text { Allocation concealment } \\
\text { (selection bias) }\end{array}$ & Low risk & $\begin{array}{l}\text { Allocation by drawing the next numbered envelope from a batch of 20, thor- } \\
\text { oughly mixed but sequentially numbered envelopes }\end{array}$ \\
\hline
\end{tabular}

Fortune 1987

\begin{tabular}{ll}
\hline Methods & Randomised controlled trial \\
\hline Participants & $\begin{array}{l}25 \text { patients with acute injury and haemorrhage, hypotensive, urine output }<20 \mathrm{ml} / \mathrm{hr} \\
\text { Mean age }=46 \\
\text { Exclusion: history of myocardial infarction in previous year as a higher haematocrit could be harmful }\end{array}$ \\
\hline Interventions & $\begin{array}{l}\text { 1. } \geq 5 \text { units of blood to maintain Haematocrit at } 40 \%(\mathrm{n}=13) \\
\text { 2. }<5 \text { units of blood transfusion to maintain haematocrit at } 30 \%(\mathrm{n}=12)\end{array}$ \\
\hline Outcomes & cardiopulmonary status \\
\hline Notes & $\begin{array}{l}\text { Study was designed to test the hypothesis that sufficient oxygen can be provided at lower haematocrit } \\
\text { of } 30 \% . \\
\text { Allocation concealment was later reported to be adequate when co-author was contacted. }\end{array}$
\end{tabular}

\section{Risk of bias}

\begin{tabular}{lll}
\hline Bias & Authors' judgement & Support for judgement \\
\hline $\begin{array}{l}\text { Allocation concealment } \\
\text { (selection bias) }\end{array}$ & Low risk & $\begin{array}{l}\text { Quote: 'Random allocations generated by a statistician blinded to the study, in } \\
\text { sets of sealed opaque envelopes.' (Direct contact with the study author) }\end{array}$ \\
\hline
\end{tabular}

Turner 2000

\begin{tabular}{ll}
\hline Methods & $\begin{array}{l}\text { Randomised controlled trial (of paramedics using computer-generated random numbers, stratified by } \\
\text { base stations) }\end{array}$ \\
\hline Participants & $\begin{array}{l}1309 \text { trauma patients }>16 \text { years of age } \\
\text { Exclusion: pregnancy, no vital signs }\end{array}$ \\
\hline Interventions & $\begin{array}{l}\text { 1. } \geq 1 \text { unit of fluids of Hartmann's solution and Haemacell pre-hospital }(\mathrm{n}=699) \\
\text { 2. Delayed/no fluids pre-hospital ( } \mathrm{n}=610)\end{array}$ \\
\hline \hline
\end{tabular}


Turner 2000 (Continued)

$\begin{array}{ll}\text { Outcomes } & \text { post-operative complications } \\ & \text { - process of care } \\ & \text { - costs } \\ & \text { death }\end{array}$

$\begin{array}{ll}\text { Notes } & \text { Protocol compliance was poor with } 31 \% \text { of the fluid group receiving fluids and } 80 \% \text { of the no fluid } \\ \text { group not given fluids. }\end{array}$
group not given fluids.

\section{Risk of bias}

\begin{tabular}{lll}
\hline Bias & Authors' judgement & Support for judgement \\
\hline $\begin{array}{l}\text { Allocation concealment } \\
\text { (selection bias) }\end{array}$ & High risk & $\begin{array}{l}\text { Paramedics were randomised to provide the treatment or control intervention } \\
\text { using computer-generated random numbers, stratified by base stations. The } \\
\text { paramedics crossed over to alternate fluid protocol halfway through the trial } \\
\text { and they were not blinded. There was no blinding in outcome assessment }\end{array}$ \\
\hline
\end{tabular}

Characteristics of excluded studies [ordered by study ID]

\begin{tabular}{ll}
\hline Study & Reason for exclusion \\
\hline Gondos 2010 & Fluid composition varied between intervention groups, but not timing and volume \\
\hline Yang 2013 & Not randomised. Not clear whether participants were bleeding \\
\hline
\end{tabular}

\section{AP PE N DICES}

\section{Appendix 1. Search strategies}

\section{Cochrane Inuries Group Specialised Register}

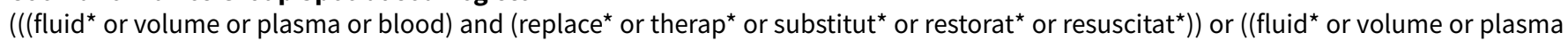
or blood) and (administrat* or challenge or perfusion or intravenous or shock))) and (timing or volume) [REFERENCE] [STANDARD]

\section{Cochrane Central Register of Controlled Trials (CENTRAL), The Cochrane Library}

\#1MeSH descriptor: [Fluid Therapy] explode all trees

\#2MeSH descriptor: [Infusions, Intravenous] explode all trees

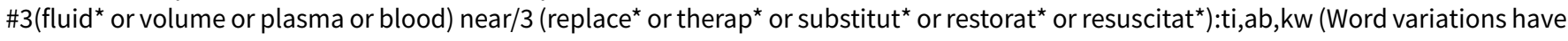
been searched)

\#4(fluid* or volume or plasma or blood) near/3 (administrat* or challenge or perfusion or intravenous or shock):ti,ab,kw (Word variations have been searched)

$\# 5$ (\#1 or \#2 or \#3 or \#4)

\#6MeSH descriptor: [Time Factors] this term only

$\# 7$ (timing or delayed or intermediate or early or selective or rapid or immediate ${ }^{\star}$ ):ti (Word variations have been searched)

\#8rapid near/3 infusion*:ti,ab,kw (Word variations have been searched)

\#9(small ${ }^{\star}$ or large ${ }^{\star}$ ) near/3 volume:ti,ab,kw (Word variations have been searched)

$\# 10 \mathrm{MeSH}$ descriptor: [Plasma Volume] explode all trees

$\# 11 \# 6$ or \#7 or \#8 or \#9 or \#10

$\# 12 \# 5$ and \#11

Ovid MEDLINE(R), Ovid MEDLINE(R) In-Process \& Other Non-Indexed Citations, Ovid MEDLINE(R) Daily and Ovid OLDMEDLINE(R)

1. exp Fluid Therapy/

2. exp Infusions, Intravenous/

3. ((fluid ${ }^{\star}$ or volume or plasma or blood) adj3 (replace* or therap* or substitut $^{\star}$ or restorat $^{\star}$ or resuscitat $\left.^{\star}\right)$ ).ab,ti. 
4. ((fluid ${ }^{\star}$ or volume or plasma or blood) adj3 (administrat* or challenge or perfusion or intravenous or shock)).ti,ab.

5. 1 or 2 or 3 or 4

6. exp Time Factors/

7. exp Plasma Volume/

8. (timing or delayed or intermediate or early or selective or rapid or immediate*).ti.

9. (rapid adj3 infusion*).ab,ti.

10. ((small* or large $\left.{ }^{\star}\right)$ adj3 volume).ab,ti.

11. 6 or 7 or 8 or 9 or 10

12.5 and 11

13. randomi?ed.ab,ti.

14. randomized controlled trial.pt.

15. controlled clinical trial.pt.

16. placebo.ab.

17. clinical trials as topic.sh.

18. randomly.ab.

19. trial.ti.

20. or/13-19

21. humans.sh.

22. 20 and 21

23. 22 and 12

\section{Embase Classic + Embase (OvidSP)}

1. exp Fluid Therapy/

2. exp Infusions, Intravenous/

3. ((fluid ${ }^{\star}$ or volume or plasma or blood) adj3 (replace or therap $^{\star}$ or substitut ${ }^{\star}$ or restorat* or resuscitat $\left.\left.^{\star}\right)\right)$.ab,ti.

4. ((fluid* or volume or plasma or blood) adj3 (administrat* or challenge or perfusion or intravenous or shock)).ti,ab.

5. 1 or 2 or 3 or 4

6. (timing or delayed or intermediate or early or selective or rapid or immediate ${ }^{\star}$ ).ti.

7. (rapid adj3 infusion*).ab,ti.

8. ((small ${ }^{\star}$ or large $\left.{ }^{\star}\right)$ adj3 volume*).ab,ti.

9. *time factors/

10. *plasma volume/

11. 6 or 7 or 8 or 9 or 10

12. 5 and 11

13. exp Randomized Controlled Trial/

14. exp controlled clinical trial/

15. randomi?ed.ab.

16. placebo.ab.

17. exp Clinical Trial/

18. randomly.ab.

19. trial.ti.

20. 13 or 14 or 15 or 16 or 17 or 18 or 19

21. exp human/

22. 20 and 21

23. 22 and 12

ISI Web of Science: Science Citation Index Expanded (SCI-EXPANDED) and Conference Proceedings Citation Index-Science (CPCI-S) $\mathrm{TI}=\left(\left(\right.\right.$ fluid $^{\star}$ or volume or plasma or blood) and (replace ${ }^{\star}$ or therap ${ }^{\star}$ or substitut ${ }^{\star}$ or restorat ${ }^{\star}$ or resuscitat $\left.\left.{ }^{\star}\right)\right)$ AND Title $=($ timing or volume) AND TS=(randomised OR randomized OR randomly OR random order OR random sequence OR random allocation OR randomly allocated $\mathrm{OR}$ at random OR randomized controlled trial OR controlled clinical trial OR randomized controlled trials) OR $\mathrm{Tl}=\left(\left(\mathrm{fluid}{ }^{*}\right.\right.$ or volume or plasma or blood) and (administrat* or challenge or perfusion or intravenous or shock)) AND TI=(timing or volume) AND TS=(randomised OR randomized OR randomly OR random order OR random sequence OR random allocation OR randomly allocated OR at random OR randomized controlled trial OR controlled clinical trial OR randomized controlled trials)

\section{Appendix 2. Search methods for previous versions}

\section{Changes to search methods}

For previous versions of this review the National Research Register (http://www.nihr.ac.uk) was searched. The database is archived and contains research projects only from 2000 to September 2007 therefore it was not searched for updates. 
PubMed was also not searched for this version: the Trials Search Co-ordinator assessed from where the included studies originated and as none were retrieved from PubMed it was considered redundant. The present list of sources in the Search Methods section was deemed sufficient.

The authors searched the following clinical trials registries for previous updates:

1. Clinicaltrials.gov (www.clinicaltrials.gov);

2. World Health Organization (WHO) International Clinical Trials Registry Platform (http://apps.who.int/trialsearch/);

3. Current Controlled Trials (http://www.controlled-trials.com/).

WHAT'S NEW

\begin{tabular}{lll}
\hline Date & Event & Description \\
\hline 10 February 2014 & $\begin{array}{l}\text { New citation required but conclusions } \\
\text { have not changed }\end{array}$ & $\begin{array}{l}\text { The review was updated to 5 February 2014. The results and con- } \\
\text { clusions have not changed. Paul Chinnock was added as an au- } \\
\text { thor. }\end{array}$ \\
\hline 10 February 2014 & New search has been performed & The review was updated to 5 February 2014. \\
\hline
\end{tabular}

\section{HISTORY}

Protocol first published: Issue 3, 2000

Review first published: Issue 1, 2001

\begin{tabular}{lll}
\hline Date & Event & Description \\
\hline 6 November 2008 & New search has been performed & $\begin{array}{l}\text { Search updated. No new trials were found for inclusion in the re- } \\
\text { view. }\end{array}$ \\
\hline 20 August 2008 & Amended & Converted to new review format. \\
\hline New search has been performed 2003 & $\begin{array}{l}\text { Data have now become available from a trial (Dutton 2002) } \\
\text { which was ongoing in 2000. These data did not affect the results } \\
\text { or the overall conclusion of the review. Types of injuries may be } \\
\text { an important consideration in the research design of future trials } \\
\text { in fluids resuscitation. }\end{array}$ \\
\hline
\end{tabular}

\section{CONTRIBUTIONSOF AUTHORS}

For all versions through 2008: IK screened citations, extracted data, contacted authors, entered data into RevMan and helped to write the review. IR developed the protocol, and helped to write the review. FB screened citations, extracted data, and commented on the review.

For the 2014 update: PC screened all the search results. FB, IR and IK screened one third each of the search results, for the purposes of dual screening. All authors decided on the exclusion of studies which did not meet the criteria for the review. All authors contributed to the final version.

\section{DECLARATIONS OF INTEREST}

None known

\section{SOURCES OF SUPPORT}

\section{Internal sources}

- Institute of Child Health, University of London, UK. 


\section{External sources}

- Global Programme on Evidence for Health Policy (GPE), World Health Organisation, Switzerland.

\section{DIFFERENCES BETWEEN PROTOCOL AND REVIEW}

Paul Chinnock was added as an author for the 2014 update.

\section{NOTES}

Note in 2014: as no studies have been identified for inclusion in this review since 2000, despite four updated searches for relevant studies, the review will be updated again in 2020.

\section{IN DEX TERMS}

\section{Medical Subject Headings (MeSH)}

Hemorrhage [complications] [*therapy]; Hypovolemia [etiology] [*therapy]; Infusions, Intravenous; Plasma Substitutes [ ${ }^{\star}$ administration \& dosage]; Randomized Controlled Trials as Topic; Time Factors; Wounds and Injuries [blood] [ ${ }^{\star}$ complications]

\section{MeSH check words}

Humans 